\title{
Centriolar Protein C2cd3 Is Required for Craniofacial Development
}

\author{
Ching-Fang Chang ${ }^{1,2}$, Kari M. Brown ${ }^{1,2}$, Yanfen Yang ${ }^{1,2}$ and Samantha A. Brugmann ${ }^{1,2,3,4 *}$ \\ ${ }^{1}$ Division of Developmental Biology, Department of Pediatrics, Cincinnati Children's Hospital Medical Center, Cincinnati, OH, \\ United States, ${ }^{2}$ Department of Pediatrics, University of Cincinnati College of Medicine, Cincinnati, OH, United States, \\ ${ }^{3}$ Division of Plastic Surgery, Department of Surgery, Cincinnati Children's Hospital Medical Center, Cincinnati, OH, \\ United States, ${ }^{4}$ Shriners Children's Hospital, Cincinnati, $\mathrm{OH}$, United States
}

OPEN ACCESS

Edited by:

Marcela Buchtova

Czech Academy of Sciences, Czechia

Reviewed by:

Zsolt Gabor Venkei,

Whitehead Institute for Biomedical

Research, United States

Zheng $\mathrm{Fu}$,

University of Virginia, United States

${ }^{*}$ Correspondence:

Samantha A. Brugmann

samantha.brugmann@cchmc.org

Specialty section:

This article was submitted to

Cell Growth and Division,

a section of the journal

Frontiers in Cell and Developmental

Biology

Received: 29 December 2020

Accepted: 17 May 2021

Published: 15 June 2021

Citation:

Chang C-F, Brown KM, Yang Y and Brugmann SA (2021) Centriolar

Protein C2cd3 Is Required

for Craniofacial Development.

Front. Cell Dev. Biol. 9:647391.

doi: 10.3389/fcell.2021.647391
The primary cilium is a ubiquitous, microtubule-based cellular organelle. Primary cilia dysfunction results in a group of disorders termed ciliopathies. C2 domain containing 3 centriole elongation regulator (C2cd3), encodes a centriolar protein essential for ciliogenesis. Mutations in human C2CD3 are associated with the human ciliopathy OralFacial-Digital syndrome type 14 (OFD14). In order to better understand the etiology of ciliopathies including OFD14, we generated numerous murine models targeting C2cd3. Initial analysis revealed several tissue-specific isoforms of $\mathrm{C} 2 \mathrm{~cd} 3$, and while the loss of C2cd3 has previously been reported to result in exencephaly, tight mesencephalic flexure, pericardial edema, abnormal heart looping and a twisted body axis, further analysis revealed that genetic background may also contribute to phenotypic variation. Additional analyses of a conditional allelic series targeting C-terminal PKC-C2 domains or the $\mathrm{N}$-terminal $\mathrm{C} 2 \mathrm{CD} 3 \mathrm{~N}-\mathrm{C} 2$ domain of $\mathrm{C} 2 \mathrm{~cd} 3$ revealed a variable degree of phenotypic severity, suggesting that while the $\mathrm{N}$-terminal $\mathrm{C} 2 \mathrm{CD} 3 \mathrm{~N}-\mathrm{C} 2$ domain was critical for early embryonic development as a whole, there was also a craniofacial specific role for the $\mathrm{C} 2 \mathrm{CD} 3 \mathrm{~N}-\mathrm{C} 2$ domains. Together, through generation of novel models and evaluation of $\mathrm{C} 2 \mathrm{~cd} 3$ expression, these data provide valuable insight into mechanisms of pathology for craniofacial ciliopathies that can be further explored in the future.

Keywords: primary cilia, ciliopathies, $\mathrm{C2cd} 3$, craniofacial development, neural crest

\section{INTRODUCTION}

The primary cilium is a cellular organelle comprised of a microtubule-based axoneme extending from the cell surface, and a basal body that resides internally at the base of axoneme. Defects in the structure or function of the ciliary complex result in a class of diseases called ciliopathies. Ciliopathies affect as many as 1 in 800 people. Currently, there are 26 known ciliopathies, 25 predicted ciliopathies and another 400 human diseases considered possible ciliopathies that have yet to be classified (Schock and Brugmann, 2017). Although ciliopathies often present with pleiotropic phenotypes including renal disease, retinal degeneration, obesity, skeletal dysplasia, and craniofacial anomalies (Reiter and Leroux, 2017), 30\% of ciliopathies are primarily classified by their craniofacial phenotypes. Craniofacial ciliopathies are most frequently defined by the combinatorial presentation of cleft lip/palate, craniosynostosis, hypertelorism, and micrognathia (Schock and Brugmann, 2017). Interestingly, among the 187 genes that are associated with known 
ciliopathies, 50 genes encode proteins that localize to basal bodies or centrosomes, and an additional five genes encode proteins that localize to centriolar satellites (Reiter and Leroux, 2017). Thus, understanding formation and function of the basal body is essential for gaining insights for therapeutic treatment of ciliopathies.

The basal body is a modified mother centriole within the centrosome. During G1-S phase of the cell cycle, the daughter centriole gradually loses its daughter centriole-specific proteins and acquires distal and subdistal appendages in late G2 phase. The acquisition of distal appendages and subdistal appendages marks the maturation of the mother centriole and distinguishes the mother centriole from the daughter centriole. During intracellular cilium assembly, Golgiderived ciliary vesicles dock and fuse at the distal end of the mother centriole, a step called centriole-to-basal body transition. The ciliary axoneme is then assembled by extension of centriolar microtubules underneath the ciliary vesicular cap, while the basal body migrates to the plasma membrane. This basal body/nascent cilium complex then docks and fuses to the plasma membrane through vesicular fusion, a process mediated by distal appendages, which is followed by the further growth and maintenance of the axoneme at the cell surface (Wang and Dynlacht, 2018). The mother centriole within the basal body, the daughter centriole, pericentriolar material (PCM), and centriolar satellites comprise the centrosome, the major microtubule organizing center (MTOC) of the cell. Components localized to the cilium and/or centrosome play essential roles in the dynamics between both organelles; therefore, regulation of the two organelles are tightly linked (Joukov and De Nicolo, 2019).

Recent studies have uncovered several key regulators of centriole maturation and subsequent ciliogenesis. For example, several distal centriolar proteins including C2 domain containing 3 centriole elongation regulator $(\mathrm{C} 2 \mathrm{~cd} 3)$, Oral-Facial-Digital Syndrome 1 Protein (Ofd1) and others are required for the recruitment of distal appendage proteins to the distal end of mother centriole (Singla et al., 2010; Ye et al., 2014; Kazatskaya et al., 2017). C2cd3 and Ofd1 colocalize and physically interact at the distal end of centriole to control centriolar length. Ofd1 acts as a negative regulator of centriole elongation, constraining centriole elongation (Singla et al., 2010). Conversely, C2cd3 is a positive regulator of centriole elongation, as loss of $\mathrm{C} 2 \mathrm{~cd} 3$ results in shorter centrioles and overexpression of $\mathrm{C} 2 \mathrm{~cd} 3$ produces hyperelongated centrioles. More intriguingly, this hyper-elongated centriole can be suppressed by Ofd1 (Thauvin-Robinet et al., 2014). While several other centriolar proteins are required for centriole maturation, elongation, and uncapping (Hsiao et al., 2009; Schmidt et al., 2012; Burke et al., 2014; Kobayashi et al., 2014; Lu et al., 2015; Bhattacharyya et al., 2016), C2cd3 and Ofd1 have been a focus of study because of their association with the human ciliopathy Oral-facialdigital syndrome (OFD).

Oral-facial-digital syndromes represent a group of human ciliopathies caused by mutations to various ciliary proteins. OFDs can be characterized by facial, oral and digital malformations. To date, there are approximately 18 subtypes of OFD syndromes, ${ }^{1}$ and each subtype is classified according to the associated gene. Although affected individuals in each subtype present with largely overlapping phenotypes, they do have distinct and unique clinical features. For example, whereas patients with OFD IV display severe tibial dysplasia, patients with OFD VI display cerebellar abnormalities, and patients with OFD IX are characterized by retinal coloboma, in addition to oral, facial and digital defects. Among the subtypes in which causative genes have been identified, almost all genes express proteins which localize to the basal body (Cortes et al., 2016; Franco and Thauvin-Robinet, 2016; Bruel et al., 2017). For example, the most frequent OFD subtype, OFD $\mathrm{I}$, is associated with mutations in OFD1, which encodes a protein localized to the basal body. Mutations in NEK1, a centrosomal protein responsible for centriole elongation, are associated with OFD II.

Mutations in $\mathrm{C} 2 \mathrm{CD} 3$ are associated with OFD14. C2CD3 contains a tandem array of five classical Protein Kinase C C2 domains (PKC-C2) and a novel, divergent C2CD3 N-terminal C2 (C2CD3N-C2) domain (Zhang and Aravind, 2012). C2 domains are present in many proteins and were first discovered as calciumdependent membrane-targeting domains in the conventional (or $\mathrm{Ca}^{2+}$-activated) PKC isoforms $(\alpha, \beta, \gamma)$ (Steinberg, 2008; Farah and Sossin, 2012); however, a variety of C2 domains that have $\mathrm{Ca}^{2+}$-independent membrane-targeting abilities have also been identified (Lee et al., 1999; Djordjevic and Driscoll, 2002). While the PKC-C2 domain predicts membrane-anchoring function of $\mathrm{C} 2 \mathrm{CD} 3$, the function of the divergent $\mathrm{C} 2 \mathrm{CD} 3 \mathrm{~N}-\mathrm{C} 2$ domain remains unknown (Zhang and Aravind, 2012). Over $70 \%$ of identified OFD14 causing $\mathrm{C} 2 \mathrm{CD} 3$ mutations are located within $\mathrm{PKC}-\mathrm{C} 2$ or $\mathrm{C} 2 \mathrm{CD} 3 \mathrm{~N}-\mathrm{C} 2$ domains, further suggesting the importance for understanding the role of each domain (Boczek et al., 2018).

More recently murine and avian models for OFD14 have been used to examine C2CD3 function. Hearty (Hty), a recessive lethal mouse mutant identified by forward genetic screening, showed severe developmental defects including those of the neural tube, heart and limb (Hoover et al., 2008). The Hty mutation resulted in a largely truncated protein, which contained the divergent $\mathrm{C} 2 \mathrm{CD} 3 \mathrm{~N}-\mathrm{C} 2$ domain but none of the more C-terminal PKCC2 domains. talpid ${ }^{2}\left(t^{2}\right)$, a naturally occurring avian mutant, was recently identified as being caused by a 19 bp deletion in exon 32 of C2CD3 (Chang et al., 2014). Long gestational survival of $t a^{2}$ has allowed for additional analyses and determination that it is a bona fide model for OFD14. Mutations in $\mathrm{C} 2 \mathrm{~cd} 3$ impair the formation and function of primary cilia, and perhaps most notably the transduction of cilia-dependent Hedgehog signaling (Hoover et al., 2008; Chang et al., 2014). Moreover, migration and differentiation of cranial neural crest cells were affected in $t a^{2}$, suggesting a possible cellular etiology of OFD14 (Chang et al., 2014; Schock et al., 2015). Although $t a^{2}$ is a model for human OFD14, the lack of avian genetic techniques necessitates murine models for further mechanistic and tissuedependent study.

\footnotetext{
${ }^{1}$ https://www.omim.org
} 
Here we report and characterize several novel $\mathrm{C} 2 \mathrm{~cd} 3$ mouse models, including a publicly available conditional knockout line and two novel CRISPR-targeted lines, targeting regions in the divergent $\mathrm{C} 2 \mathrm{CD} 3 \mathrm{~N}-\mathrm{C} 2$ domain or PKC-C2 domains. We identified the predominant $\mathrm{C} 2 \mathrm{~cd} 3$ isoforms in a tissue-specific manner and propose that phenotypic variability is a consequence of both tissue-specific isoforms and genetic background. In sum, data presented herein can be used not only to study the etiology of ciliopathic pathologies, but also to address the specific roles of various C2-domains during development.

\section{RESULTS}

\section{C2cd3 Is Dynamically Expressed During Embryonic and Craniofacial Development}

Despite an accepted role in ciliogenesis, $C 2 c d 3$ expression has not been well documented during embryogenesis or craniofacial development. To comprehensively characterize $C 2 c d 3$ expression, $C 2 c d 3^{T M 1 a(E U C O M M) W t s i}$ mouse ES cells were injected into mouse blastocysts. Recovered transgenic mice (hereafter referred to as $\mathrm{C} 2 c d 3^{\mathrm{LacZ}}$ ) expressed a $\mathrm{LacZ}$-expression cassette after exon 3 of $C 2 c d 3$, as well as LoxP sites flanking exon 4/5 for the option of tissue-specific gene deletion using Cre-LoxP system (Figure 1A). Heterozygous $\mathrm{C} 2 c d 3^{\mathrm{LacZ} /+}$ mice were viable and morphologically normal, while homozygous C2cd3 ${ }^{\mathrm{LacZ} / \mathrm{LacZ}}$ mice died at approximately E10.5 (data not shown). Whole mount X-gal staining revealed that $\mathrm{C} 2 c d 3$ was expressed ubiquitously at E10.5 (Figure 1B). At E11.5, however, $\mathrm{C} 2 \mathrm{c} d 3$ expression was more spatially distinct with the most robust expression in the neural epithelium, optic cup, oral epithelium, and tongue mesenchyme (Figure 1C). Ubiquitous, but variable levels of $\mathrm{C} 2 \mathrm{~cd} 3$ protein isoforms $(255,232$, and $205 \mathrm{kDa})$ were detected in various embryonic tissues at E11.5 via Western blot analysis (Figure 1D asterisks and Supplementary Figure 1). The $255 \mathrm{kDa}$ isoform was expressed at varible levels across all isolated tissues (brain, face, heart, limb, and liver) (Figure 1D, top asterisk). The $232 \mathrm{kDa}$ isoform was also detected across all tissues, albiet at much lower levels (Figure 1D, middle asterisk). The $205 \mathrm{kDa}$ isoform was distinct from other isoforms, as it was robustly expressed in heart tissue (Figure 1D, bottom asterisk). While protein prediction tools predicted an additional $214 \mathrm{kDa}$ isoform, we were unable to detect it due to the lack of the C-terminal epitope which the antibody recognizes (Supplementary Figure 1). C2cd3 expression was maintained later in development in both epithelial and mesenchymal tissues, including the lateral ganglionic eminence and ventricular zone of developing neocortex, perichondrium of developing cranial bones, palatal epithelium, oral epithelium, and mesenchyme surrounding Meckel's cartilage at E14.5 (Figure 1E). Together, these results suggested that $C 2 c d 3$ expression was dynamic throughout embryonic and craniofacial development. We next sought to examine the consequences of impaired $\mathrm{C} 2 \mathrm{c} d 3$ expression.
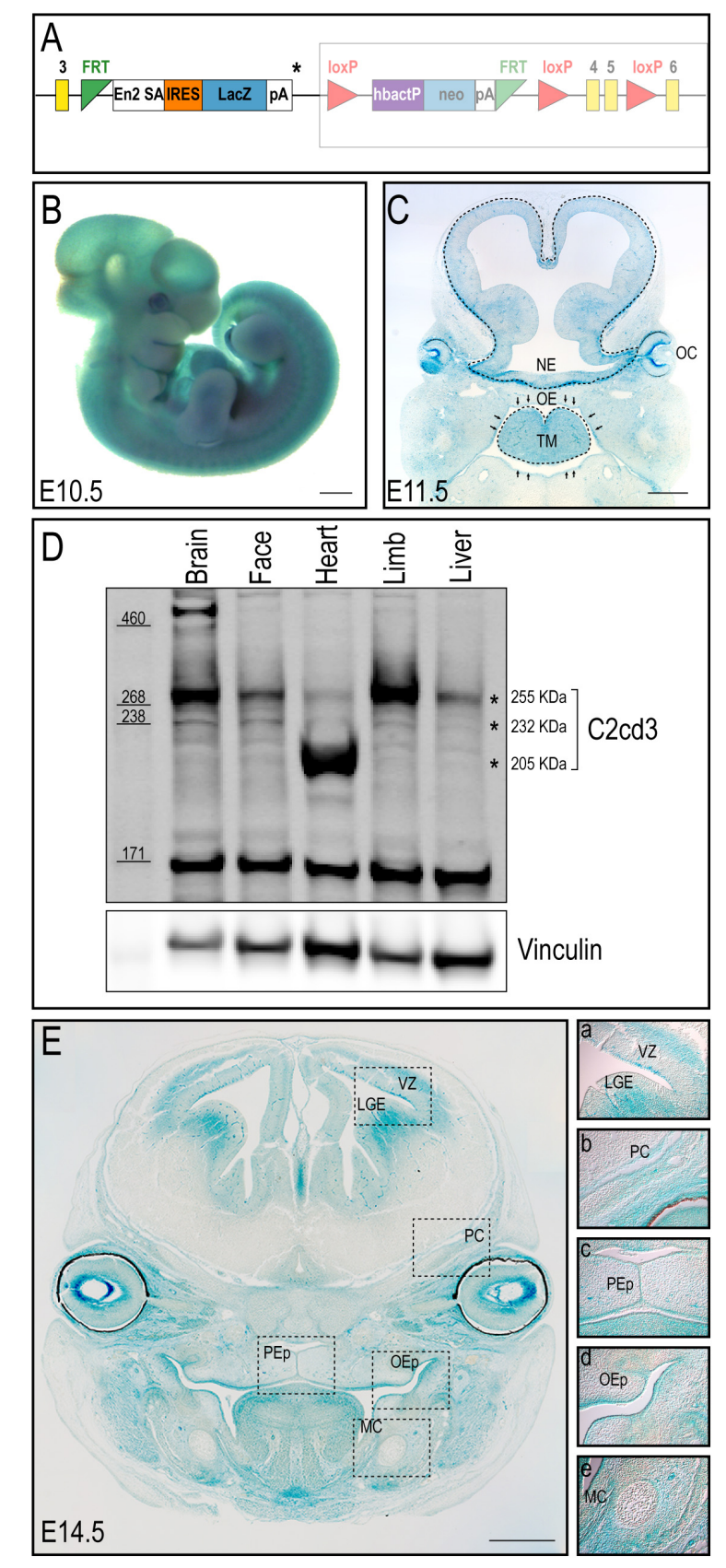

FIGURE 1 | C2cd3 expression in developing mouse embryos. (A) Schematic of $C 2 c d 3^{\text {LacZ }}$ targeted allele. LacZ expression cassette containing a stop codon (*) was inserted after exon (yellow box) 3. The remaining, unexpressed part of the construct designed for conditional knockout is indicated in the shaded box. (B) Whole mount X-gal staining indicates ubiquitous C2cd3 expression in E10.5 embryos. (C) Frontal section of an E11.5 embryo showing robust C2cd3 expression in neural epithelium (NE, dotted line), otic cup (OC), oral epithelium (OE, arrows) and tongue mesenchyme (TM, dotted line).

(D) Western blot of C2cd3 expression in different tissues of E11.5 wild type embryos, showing three C2cd3 isoforms (asterisks). (E) Frontal section of E14.5 embryo, revealing robust C2cd3 expression in the lateral ganglionic eminence (LGE) and ventricle zone (VZ) of developing neocortex, perichondrium (PC) of developing cranial bones, palatal epithelium (PEp), oral epithelium (OEp) and mesenchyme surrounding Meckel's cartilage (MC). All scale bars: $0.5 \mathrm{~mm}$. 


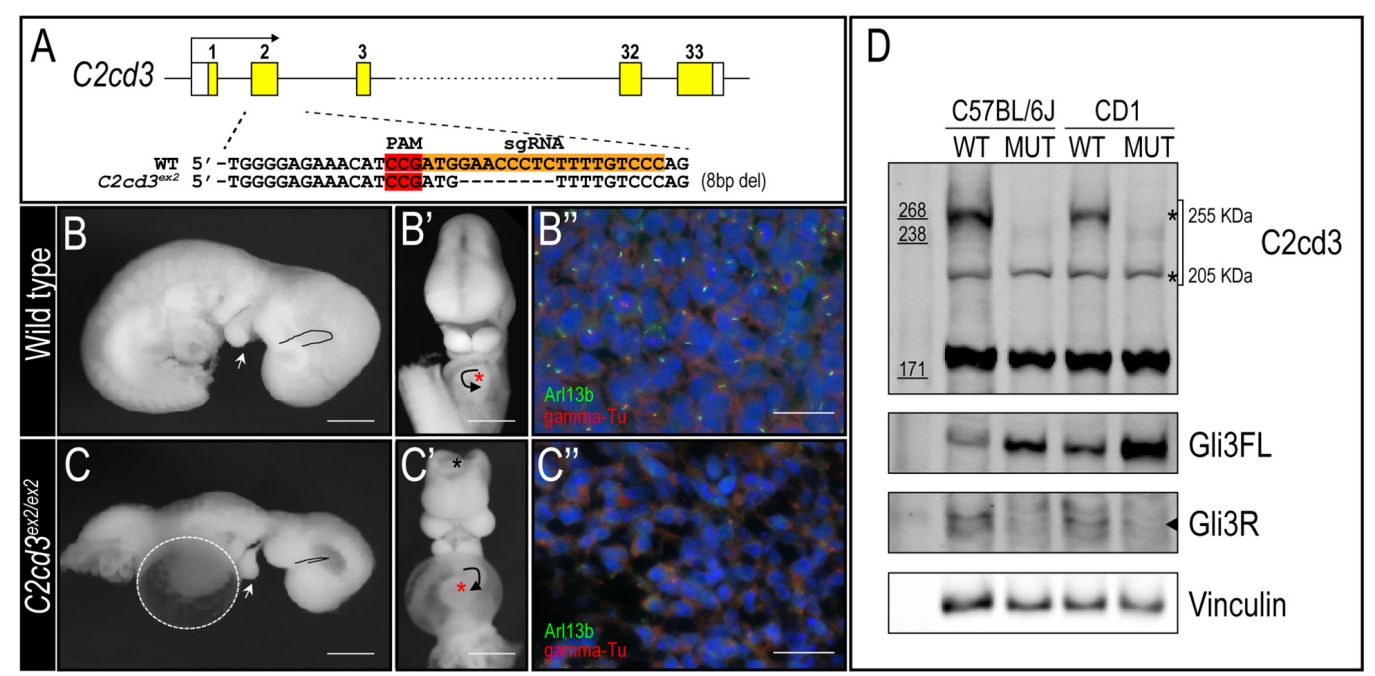

FIGURE 2 | $C 2 c d 3^{e x 2 / e x 2}$ mutants present with phenotypes indicative of a ciliopathy. (A) Schematic of CRISPR-targeted 8 bp deletion in C2cd3 at exon 2 which results in a premature stop codon. (B,C) Lateral and $\left(\mathbf{B}^{\prime}, \mathbf{C}^{\prime}\right)$ frontal views of E9.5 wild-type and C2cd3ex2/ex2 embryos. C2cd3ex2/ex2 embryos exhibit pericardial edema (white dashed line), tight mesencephalic flexure (black line), mandibular hypoplasia (white arrowhead), abnormal heart looping (black arrow), and exencephaly

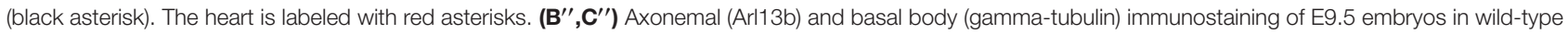

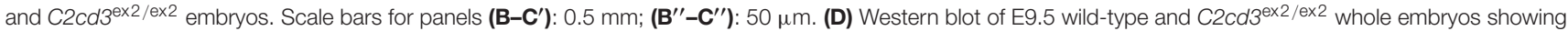
deletion of the $255 \mathrm{kDa}$ isoform in both C57BL/6J and CD1 backgrounds. The ratio of Gli3FL/Gli3R is increased in C2cd3ex2/ex2 compared to wild-type.

\section{C2cd3 Mutants Present With Multiple Embryonic Defects}

To better understand the biological function of $C 2 c d 3$, we utilized CRISPR-mediated genome editing to generate an 8 bp deletion in exon 2 that resulted in a premature stop codon (henceforth referred to as $C 2 c d 3^{\text {ex } 2}$ ) (Figure 2A). $C 2 c d 3^{\mathrm{ex} 2 / \mathrm{ex} 2}$ mutants were embryonic lethal at approximately E10.5 and presented with phenotypes similar to those previously reported in Hty mutants (Hoover et al., 2008). Mutants were present in Mendelian ratios (Table 1A) and $90 \%$ of mutants exhibited exencephaly and a twisted body axis (Figures 2B-C and Table 1B). In addition, $30 \%$ of $C 2 c d 3^{\operatorname{ex} 2 / \operatorname{ex} 2}$ mutants presented with pericardial edema, abnormal heart looping, and a tight mesencephalic flexure (Figures 2B-C' and Table 1B). Compared to the previously reported $\mathrm{C} 2 \mathrm{~cd} 3$ Hty mutants, which commonly presented with twisted body axis, pericardial edema, and tight mesencephalic flexure, the most common phenotypes in $C 2 c d 3^{\operatorname{ex} 2 / e x 2}$ mutants were exencephaly and twisted body axis. Although polydactyly was also observed in Hty mutants at E12.5, we were unable to assess this phenotype in $C 2 c d 3^{\mathrm{ex} 2 / \mathrm{ex} 2}$ mutants because they did not survive past E10.5. To confirm that $C 2 c d 3^{\mathrm{ex} 2 / \mathrm{ex} 2}$ mutants failed to extend primary cilia, immunostaining for Arl13b (ciliary axoneme) and gamma-tubulin (basal body) was performed. Relative to the facial mesenchyme of wild-type embryos, $C 2 c d 3^{\text {ex2/ex2 }}$ mutants lacked Arl13b while maintaining gammatubulin staining, indicating that the extension of primary cilia was abolished but the basal body remained intact (Figure $\mathbf{2} \mathbf{B}^{\prime \prime}, \mathbf{C}^{\prime \prime}$ ). Thus, $C 2 c d 3^{\mathrm{ex} 2 / \mathrm{ex} 2}$ mutants lacked cilia and presented with phenotypes indicative of a ciliopathic model.

Genetic modifiers have been hypothesized to alter phenotypic presentation associated with mutations in ciliary genes (Reiter and Leroux, 2017). Given the variation in phenotypic penetrance between Hty (C3H/HeN background) and $C 2 c d 3^{\operatorname{ex} 2 / e x 2}$ mutants, we examined if background strain contributed to severity and degree of penetrance in $C 2 c d 3^{\mathrm{ex} 2 / \mathrm{ex} 2}$ mutants. The $C 2 c d 3^{\mathrm{ex} 2}$ line was generated on an outbred CD1 background, and backcrossed over seven generations onto the inbred C57BL/6J background. We observed that embryos with abnormal heart looping, pericardial edema, and tight mesencephalic flexure

TABLE 1 | Phenotypic presentations of C2cd3 mutants. (A) Total number of wild-type, $C 2 c d 3^{\mathrm{e} 2} 2 /+$, and $C 2 c d 3^{\mathrm{e} 2} / \mathrm{e} \times 2$ embryos, $n=$ number of litters on CD1 and C57BL/6J backgrounds. (B) Percentages of phenotypes present in C2cd3 ${ }^{\mathrm{ex} 2 / \mathrm{e} 2}$ mutant embryos.

TABLE 1A | Number of wild-type, C2cd3 ex2/+, and C2cd3 ex2/ex2 embryos on CD1 and C57BL/6J backgrounds.

\begin{tabular}{llllll}
\hline Background & Total & $\boldsymbol{n}$ & Wild-type & Het & Mutant \\
\hline Outcrossed CD1 & 52 & 4 & $13(25 \%)$ & $29(56 \%)$ & $10(19 \%)$ \\
Backcrossed C57BL/6J F4 & 48 & 6 & $13(27 \%)$ & $26(54 \%)$ & $9(19 \%)$
\end{tabular}

TABLE 1B | Observed phenotypic penetrance of C2cd3 $3^{\mathrm{ex} 2 / \mathrm{ex} 2}$ mutants on CD1 and C57BL/6J backgrounds.

\begin{tabular}{lcc}
\hline Phenotype & Outcrossed & Backcrossed \\
\cline { 2 - 3 } & $\begin{array}{c}\text { CD1 } \\
(\boldsymbol{n}=\mathbf{1 0 )}\end{array}$ & $\begin{array}{c}\text { C57BL/6J F4 } \\
(\boldsymbol{n}=\mathbf{9})\end{array}$ \\
\hline Exencephaly & $9(90 \%)$ & $6(67 \%)$ \\
Tight mesencephalic flexure & $3(30 \%)$ & $3(33 \%)$ \\
Abnormal heart looping & $3(30 \%)$ & $5(56 \%)$ \\
Twisted body axis & $9(90 \%)$ & $7(78 \%)$ \\
Pericardial edema & $3(30 \%)$ & $4(44 \%)$
\end{tabular}


TABLE 2 | Percentage of diagnostic alleles present in C2cd3ex2/+ mice on CD1 and C57BL/6J backgrounds.

\begin{tabular}{lc}
\hline Background & C57BL/6J substrain, \% \\
\hline CD1 & 28.6 \\
CD1;C57BL/6J, F2 & 97.4 \\
CD1;C57BL/6J, F7 & 98.1 \\
\hline
\end{tabular}

increased from $30 \%$ on a CD1 background to 56,44 , and $33 \%$, respectively on a C57BL/6J:CD1 mixed background, whereas the percentage of embryos showing exencephaly and twisted body phenotypes was reduced (Table 1B, C57BL/6J, F4). The purity of genetic background was examined by miniMUGA (Mouse Universal Genotyping Array) analysis. $C 2 c d 3^{\text {ex } 2 /+}$ embyros on an outbred CD1 background possessed $28.6 \%$ of the potential diagnostic alleles for C57BL/6J (Table 2). In subsequent crosses on the C57BL/6J background, approximately $97 \%$ of the potential diagnostic alleles were observed in F2 mice and 98\% in F7 mice.

In light of these variable phenotypic presentations, we examined $\mathrm{C} 2 \mathrm{CD} 3$ protein expression in both control and $C 2 c d 3^{\text {ex2/ex2 }}$ mutants on C57BL/6J and CD1 backgrounds. Lysates from E9.5 whole embryos of C57BL/6J or CD1 background revealed that the expression of the $255 \mathrm{kDa}$ isoform was lost in mutant embryos on both genetic backgrounds, while the $205 \mathrm{kDa}$ isoform was maintained (Figure 2D, top and bottom asterisks, respectively). Interestingly, $232 \mathrm{kDa}$ isoform was undetectable likely because the lysate was collected from whole embryos instead of specific tissue. As deletion of primary cilia often results in aberrant Gli protein processing, we also assayed for Gli3 full length (Gli3FL) and Gli3 repressor (Gli3R) expression in $C 2 c d 3^{\operatorname{ex} 2 / \operatorname{ex} 2}$ mutants. While $C 2 c d 3^{\operatorname{ex} 2 / \mathrm{ex} 2}$ mutants on either background exhibited impaired Gli3 processing, the total amount of Gli3 protein was more robust in embryos on the CD1 background and the ratio between Gli3FL and Gli3R was higher on C57BL/6J background (Figure 2D and Supplementary Figure 2). Thus, variation in Gli3 protein expression and the Gli3FL/R ratio could contribute to changes in expressivity of phenotypes as the mutation was backcrossed onto a C57BL/6J background.

\section{C2cd3 Is Required for Craniofacial Development}

The majority of craniofacial malformations associated with mutations in $\mathrm{C} 2 \mathrm{~cd} 3$ and OFD14 stem from neural crest derived tissues. Early embryonic lethality in $C 2 c d 3^{\operatorname{ex} 2 / e x 2}$ mutants prevented an indepth examination of neural crest and craniofacial development. To better understand the function and processing of $C 2 c d 3$ relative to craniofacial development, we generated two conditional murine mutants targeting distinct protein domains, and crossed them to neural crest specific drivers.

As the name implies, $\mathrm{C} 2 \mathrm{~cd} 3$ contains an array of five classical PKC-C2 domains which are predicted to be involved in targeting proteins to the cell membrane. Despite the presence of these domains, there has been very little exploration into their distinct role relative to $\mathrm{C} 2 \mathrm{CD} 3$ function, specifically during craniofacial development. To examine the role of PKC-C2 domains, we generated a conditional mouse line in which LoxP sequences flanked exon $9\left(C 2 c d 3^{\text {ex } 9-f l o x}\right.$, Figures $\left.\mathbf{3 A}, \mathbf{A}^{\prime}\right)$. Exon 9 was chosen because upon Cre recombination, all PKC-C2 domains would be excised, generating a 445 aa truncated protein. Moreover, all the $C 2 c d 3$ splice variants containing exon 9 were recombined when Cre was expressed. Western blot analysis in wild-type and $C 2 c d 3^{\text {ex9fl/fl }}$;Wnt1-Cre embryos confirmed the loss of the 255 and $232 \mathrm{kDa}$ isoforms in E11.5 mutant facial prominences (Figure 3B). Mutant facial prominences also exhibited increased Gli3FL/Gli3R ratio (Figure 3B), indicating the cilia were functionally impaired. $C 2 c d 3^{\mathrm{ex} 9 \mathrm{fl} / \mathrm{fl}} ; \mathrm{Wnt} 1-\mathrm{Cre}$ mutant mice survived until late gestation (E18.5) and presented with phenotypes common in OFD14, including cleft palate and a dysmorphic tongue (Figures 3C-D'). Whole mount skeletal staining as well as microCT analysis of E17.5 embryos did not show defects in frontal bone or frontal suture formation (Figures 3E-F' and Supplementary Figure 4), but revealed delayed ossification of palatine bone in $\mathrm{C} 2 c d 3^{\mathrm{ex} 9 \mathrm{fl} / \mathrm{fl}} ;$ Wnt1-Cre mutant embryos (Figures 3G-H').

In addition to the array of PKC-C2 domains, $\mathrm{C} 2 \mathrm{~cd} 3$ also contains a divergent $\mathrm{C} 2 \mathrm{CD} 3 \mathrm{~N}-\mathrm{C} 2$ domain at the $\mathrm{N}$-terminus of the protein. While this domain is conserved among various species (Zhang and Aravind, 2012), the function of C2CD3N-C2 domain remains completely unknown. To determine the role of the $\mathrm{C} 2 \mathrm{CD} 3 \mathrm{~N}-\mathrm{C} 2$ domain, $\mathrm{C} 2 \mathrm{~cd} 3^{\mathrm{LacZ}}$ mice were bred to FLPeR mice (Farley et al., 2000) to excise the LacZ expression cassette (Figure 4A). The resulting progeny $\left(C 2 c d 3^{\operatorname{ex} 4-5-\text { flox }}\right)$, in which LoxP sequences flanked exon 4 and 5, generated a protein with a truncated $\mathrm{C} 2 \mathrm{CD} 3 \mathrm{~N}-\mathrm{C} 2$ domain (Figure $\mathbf{4 A}^{\prime}$ ). To assess the C2CD3N-C2 domain in neural crest cells, we utilized the Wnt1-Cre2 driver (Lewis et al., 2013) and assayed protein expression in facial prominences of E11.5 embryos via Western Blot analysis. Relative to wild-type embryos, the $255 \mathrm{kDa}$ isoform of $\mathrm{C} 2 \mathrm{~cd} 3$ was lost in $\mathrm{C} 2 \mathrm{~cd} 3^{\mathrm{ex} 4-5 \mathrm{fl} / \mathrm{fl}}$;Wnt1Cre 2 facial prominences. Interestingly, the $232 \mathrm{kDa}$ isoform remained detectable in mutants (Figure 4B), suggesting that the $255 \mathrm{kDa}$ isoform is required craniofacial development. Typical of many ciliopathic mutants, $C 2 c d 3^{\text {ex4-5fl/fl }}$; Wnt1Cre 2 embryos also displayed an increased Gli3FL/Gli3R ratio (Figure 4B). C2cd3 $3^{\mathrm{ex} 4-5 \mathrm{fl} / \mathrm{fl}} ; \mathrm{Wnt} 1-\mathrm{Cre} 2$ mutants survived until late gestation (E18.5). Contrary to $C 2 c d 3^{\text {ex } 9 \mathrm{fl} / \mathrm{fl}} ;$ Wnt1-Cre mutants which didn't reveal a phenotype until approximately E15.5, C2cd3 $3^{\text {ex } 4-5 \mathrm{fl} / \mathrm{fl}}$;Wnt1-Cre2 phenotypes were detected as early as E11.5, with characteristic midline widening (Figures $4 \mathbf{C}, \mathbf{C}^{\prime}$, dotted line), which was exacerbated by E15.5 (Figures 4D,D', dotted line). C2cd $3^{\mathrm{ex} 4-5 \mathrm{fl} / \mathrm{fl}} ;$ Wnt1-Cre2 mutants also presented with cleft palate (Figures $4 \mathbf{E}, \mathbf{E}^{\prime}$, dotted line) and a hypoplastic tongue (Figures $\mathbf{4 F}, \mathbf{F}^{\prime}$, asterisk). Thus, relative to $C 2 c d 3^{\mathrm{ex} 9 \mathrm{fl} / \mathrm{fl}} ;$ Wnt1-Cre, C $2 c d 3^{\mathrm{ex} 4-5 \mathrm{fl} / \mathrm{fl}} ;$ Wnt1-Cre 2 mutants had an earlier onset of craniofacial phenotypes that were more severe in nature. Whole mount skeletal staining of E18.5 $C 2 c d 3^{\text {ex4-5fl/fl}}$;Wnt1-Cre2 mutants did not reveal defects in frontal bones or frontal suture (Figures $4 \mathbf{G}-\mathbf{H}^{\prime}$ ), but exhibited delayed ossifications in sphenoid (Figures 4J,J', black arrowhead) and palatine bones (Figures 4J,J', white arrowhead) near the cranial base (Figures $4 \mathbf{I}-\mathbf{J}^{\prime}$ ). These results 

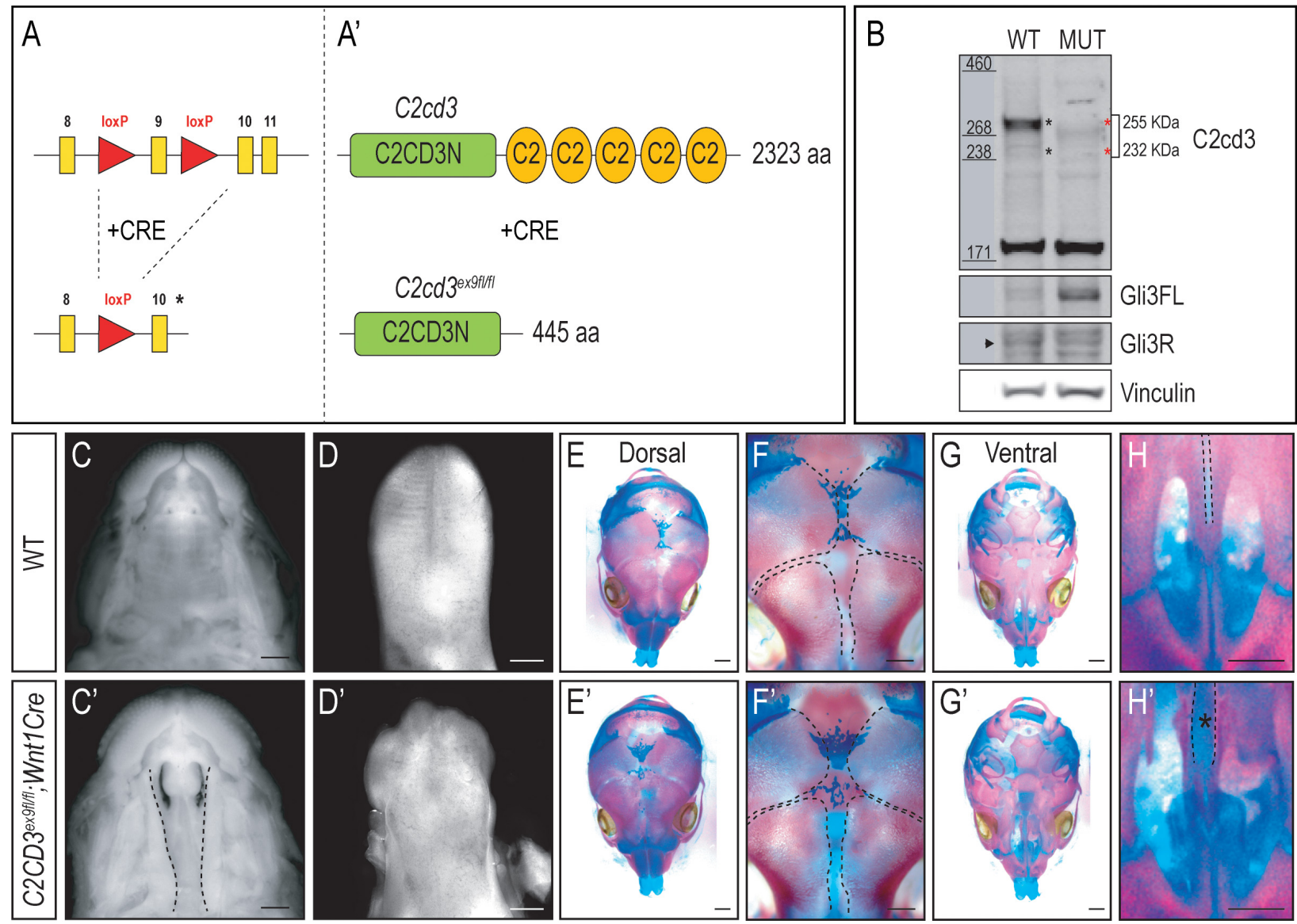

FIGURE 3 | Conditional loss of PKC-C2 domains of C2cd3 results in craniofacial phenotypes. (A,A') Schematic of conditional mouse line generated by CRISPR-targeting with LoxP sequences flanking exon 9. (B) Western blot of C2cd3 expression in E11.5 facial prominences showing deletion of the 255 and $232 \mathrm{kDa}$ isoforms in and C2cd3 ${ }^{\text {ex9fl/fl } ; W n t 1-C r e ~ e m b r y o s ~(r e d ~ a s t e r i s k s, ~} n=4$ for both wild type and mutant, not shown). (C,C') Palatal and (D,, $\mathbf{D}^{\prime}$ ) glossal views of

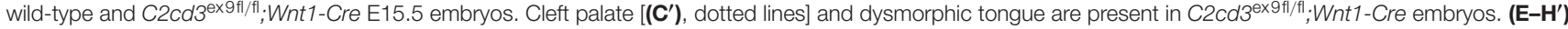

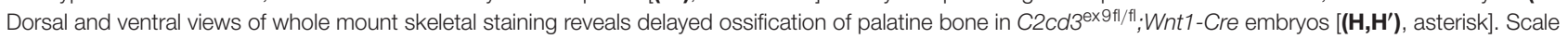
bars: $0.5 \mathrm{~mm}$.

suggested that the $\mathrm{C} 2 \mathrm{CD} 3 \mathrm{~N}-\mathrm{C} 2$ domain also plays a functional role during neural crest and craniofacial development, distinct from PKC-C2 domains.

\section{DISCUSSION}

Ciliopathies represent a growing disease class with a significant impact on craniofacial development. As no treatments are currently available for these disorders, gaining increased mechanistic understanding of their etiology through model systems is vitally important. Herein, we report three novel animal model systems to allow for future mechanistic studies regarding the onset of ciliopathic phenotypes. Our initial analyses revealed that $C 2 c d 3$ was expressed ubiquitously during early embryonic development, and heterogeneously later in development. Robust knockdown of $C 2 c d 3$ expression via CRISPR genome editing resulted in severe developmental defects culminating in early embryonic lethality. Moreover, the phenotypic penetrance and severity varied according to genetic background. We also demonstrated that the N-terminal $\mathrm{C} 2 \mathrm{CD} 3 \mathrm{~N}-\mathrm{C} 2$ domain was functionally more critical compared to C-terminal PKC-C2 domains during craniofacial development, by examining conditional alleles with two neural crest-specific drivers. These studies not only generate several new resources for the craniofacial community, but also suggest several factors that contribute to the onset of craniofacial phenotypes in ciliopathic conditions.

\section{Variation in Ciliopathic Phenotypes Is Likely Due to Genetic Modifiers}

Variable penetrance and lack of genotype-phenotype concordance has long been a challenge for definitive diagnoses of many genetic diseases. Ciliopathies often exhibit multiple and overlapping clinical features owing to the fact that cilia extend from almost all types of cells in the body. For example, Oral-facial-digital syndrome 1-18 (OFD1-18), short-rib polydactyly syndromes (SRPS), Jeune asphyxiating thoracic 


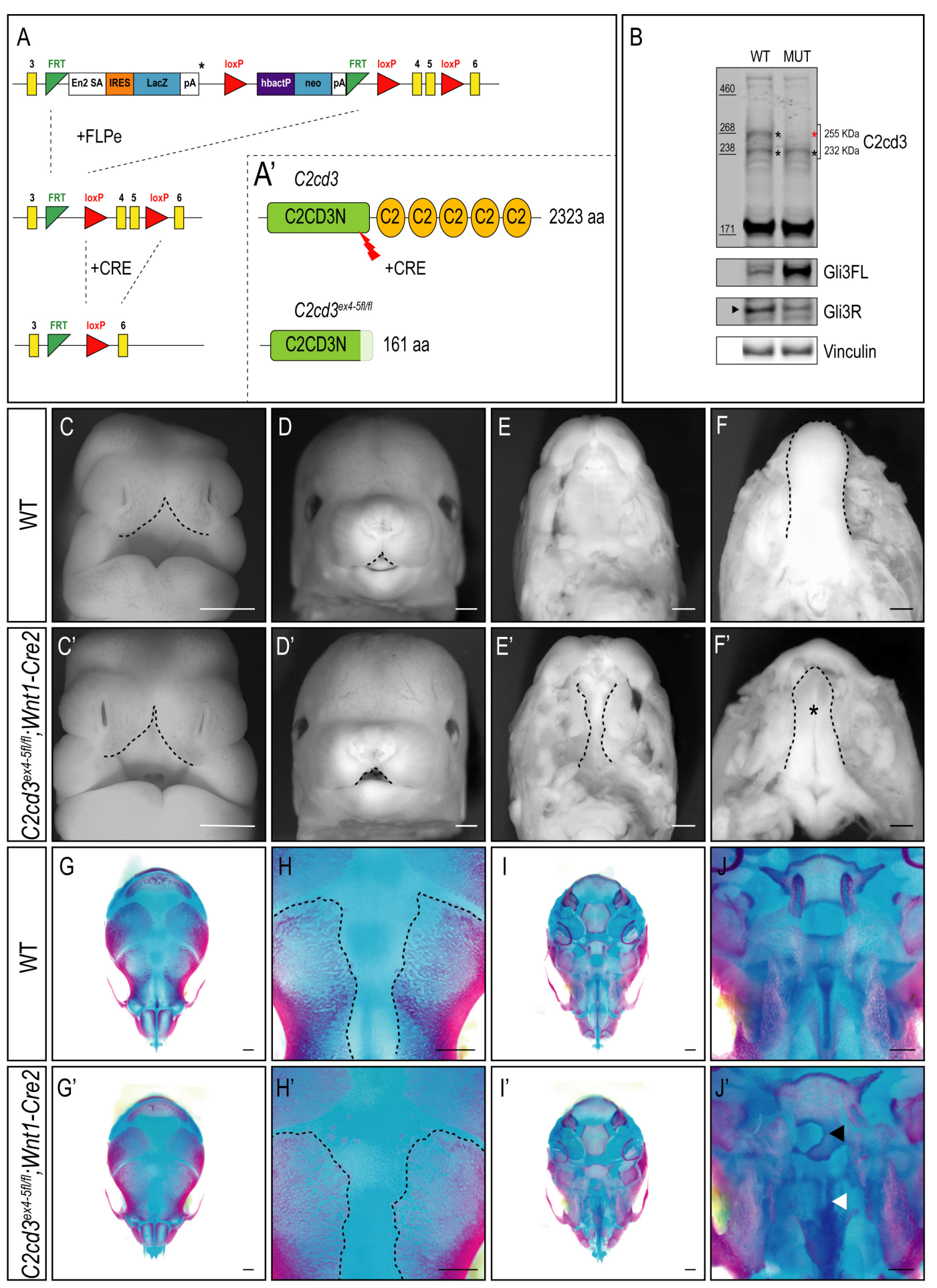

FIGURE 4 | Conditional loss of C2CD3N-C2 domain results in craniofacial phenotypes. (A,A') C2cd3 ${ }^{\text {LacZ }}$ mice were bred to FLPeR mice to excise the LacZ expression cassette, resulting in $\mathrm{C} 2 \mathrm{Cd} 3^{\mathrm{ex} 4-5 \text { flox }}$ progeny with LoxP sequences flanking exon 4 and 5 and generating a protein with a truncated $\mathrm{C} 2 \mathrm{CD} 3 \mathrm{~N}-\mathrm{C} 2$ domain. (B) Western blot of C2cd3 expression in E11.5 facial prominences showing deletion of the longest C2cd3 isoform $255 \mathrm{kDa}$ in and C2cd3 ex4-5ft/fl; Wht1-Cre (red

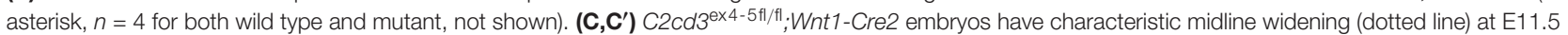

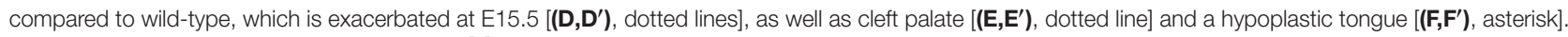
$\left(\mathbf{G}, \mathbf{G}^{\prime}\right)$ Dorsal views of skull. E18.5 C2cd3 ${ }^{\mathrm{ex} 4-5 \mathrm{ff} / \mathrm{fl}} ;$ Wht1-Cre2 embryos have normal frontal bone and frontal suture $\left(\mathbf{H}, \mathbf{H}^{\prime}\right)$ development. (I, $\left.\mathbf{I}^{\prime}\right)$ Ventral views of skull.

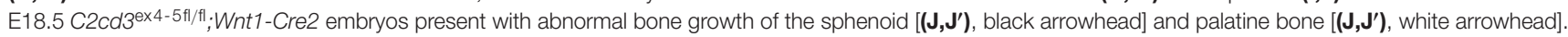
Scale bars: $0.5 \mathrm{~mm}$. 
dystrophy (JATD), Ellis van Creveld syndrome (EVC), and Cranioectodermal dysplasia (CED) all present with varied and overlapping phenotypes making diagnosis difficult. Yet, despite this understanding, the factors that contribute to variable and overlapping phenotypic presentation remain nebulous.

Studies using murine models on inbred background have provided valuable information as to the factors that contribute to phenotypic variability (Nadeau, 2001; Hamilton and Yu, 2012; Kousi and Katsanis, 2015). Numerous studies have reported different levels of phenotypic severity on various inbred backgrounds (Jones et al., 2008), as utilization of these strains can more readily identify genetic modifiers via SNP array, GigaMuga and quantitative trait locus (QTL) analysis (Morgan et al., 2015; Snedeker et al., 2019). Studies such as these have been instrumental in identifying genetic modifiers that can contribute to increasing the variability of phenotypic presentations in ciliopathies. One example of evidence of such modifiers was the report demonstrating that a $430 \mathrm{C}$ to $\mathrm{T}$ transition in MGC1203 gene (a pericentriolar protein CCDC28B that interacts with several Bardet-Biedl syndrome, BBS proteins) has an epistatic effect on BBS patients (Badano et al., 2006). While mutations in MGC1203 were insufficient to cause BBS, individual BBS patients who carry the $430 \mathrm{~T}$ variant of MGC1203 were more severely affected and have early onset retinitis pigmentosa. Another example of genetic modifiers impacting ciliopathic phenotypes was demonstrated via the relationship between AHI1 and NPHP1. Both AHI1 and NPHP1 encode ciliary proteins that physically interact, and mutations found in these two genes are associated with Joubert syndrome. Interestingly, specific variants in these genes significantly increased the risk for onset of tissue-specific phenotypes in patients (Louie et al., 2010).

Although it remains a challenge to identify genetic modifiers for disease-linked genes in humans, murine models may provide useful insight into origins of phenotypic variation. Our data indicated that the severity of phenotypic presentations in $C 2 c d 3^{\mathrm{ex} 2 / \mathrm{ex} 2}$ mutant mice is variable on different genetic background (Table 1B), suggesting there are potential genetic modifiers for $\mathrm{C} 2 \mathrm{~cd} 3$. As $\mathrm{C} 2 \mathrm{~cd} 3$ localizes to the distal end of the mother centriole and interacts with other centriolar proteins in a hierarchical manner, it is possible that any variant within proteins that localize to that area could impact phenotypic severity of $\mathrm{C} 2 \mathrm{~cd} 3$ mutations. Furthermore, hypotheses such as these could also apply to variation in human OFD patients, in terms of phenotypic presentation, diagnostic assessment and clinical outcome.

\section{Functional Roles of C2cd3 Splice Variants and Isoforms}

Most genes have multiple exons, which can contribute to specific isoforms via alternative splicing. Exons are defined by the $5^{\prime}$ splice site, the $3^{\prime}$ splice site and the branch point. These sequence elements can be recognized by the spliceosome complex, which undergoes serial events to remove the introns of pre-mRNA and to form mature mRNA. In general, exons that are used and included alternatively in the mature mRNA, have splice sites and branch point that deviate moreso than the consensus sequences present in constitutively used exons; hence, they have lower binding affinity for the spliceosome. From an evolutionary point of view, alternative splicing is used to increase diversity under different physiological conditions to affect function, binding affinity, and localizations of the protein products (Kelemen et al., 2013). Murine $C 2 c d 3$ has 33 exons and 8 splice variants. ${ }^{2}$ Among these variants, seven are protein-coding, producing four distinct protein isoforms (255, 232, 214, and $205 \mathrm{kDa}$ ), while one is a non-coding mRNA (Supplementary Figure 1). Our data revealed that while $C 2 c d 3$ was expressed ubiquitously in early developmental stages, the level of expression and the prevalence of distinct isoforms varied between different tissues. Given the variable temporal and spatial expression of $\mathrm{C} 2 c d 3$ during craniofacial development, it will be important to understand the distribution and spatial expression of individual splice variants/protein isoforms over time. Our data herein suggested that the N-terminal C2CD3N-C2 domain was more critical during craniofacial development than C-terminal $\mathrm{PKC}-\mathrm{C} 2$ domain. Interestingly, within the four $\mathrm{C} 2 \mathrm{~cd} 3$ protein isoforms there are two isoforms that contain a $\mathrm{C} 2 \mathrm{CD} 3 \mathrm{~N}-\mathrm{C} 2$ domain (255 and $214 \mathrm{kDa}$; Supplementary Figures 1A,C). We hypothesize that these two isoforms are expressed in tissues most affected in $C 2 c d 3^{\mathrm{ex} 2 / \mathrm{ex} 2}$ or $C 2 c d 3^{\mathrm{ex} 4-5 \mathrm{fl} / \mathrm{fl}} ;$ Wnt $1 C r e 2$ mutants, in which the targeted mutations disrupt C2CD3N-C2 domain. Alternatively, we hypothesize that isoforms without a C2CD3NC2 domain (232 and 205 kDa; Supplementary Figures 1B,D) are dispensable for craniofacial development, as the $232 \mathrm{kDa}$ isoform is still expressed $C 2 c d 3^{\text {ex } 4-5 \mathrm{fl} / \mathrm{fl}} ; W n t 1 C r e 2$ facial mesenchyme. Our future studies will focus on the spatial expressions and specialized functions for each $\mathrm{C} 2 \mathrm{~cd} 3$ isoform expressed in craniofacial tissues.

\section{A Role for the C2CD3N-C2 Domain During Ciliogenesis and Protein-Protein Interaction}

Many ciliary proteins in the transition zone contain both classical PKC-C2 and novel C2-domains. These domains have been hypothesized to serve as a functional interaction module within the transition zone (Zhang and Aravind, 2010, 2012; Remans et al., 2014). Although the classical PKC-C2 domain contains a $\mathrm{Ca}^{2+}$-binding pocket, which makes contact with the plasma membrane, all other C2 domains within the superfamily do not bind $\mathrm{Ca}^{2+}$ (Zhang and Aravind, 2010). Moreover, novel $\mathrm{C} 2$ domains, including the $\mathrm{C} 2 \mathrm{CD} 3 \mathrm{~N}-\mathrm{C} 2$ domain, have a unique sequence and are highly conserved among different orthologs, yet share little sequence homology to other known C2 domains. For example, a recent study reported that centriolar protein CEP120 possessed three $\mathrm{Ca}^{2+}$-independent, novel C2 domains that potentially played a role in mediating microtubulebinding (Sharma et al., 2018). Our data provide further evidence for the functional importance of a non-classical C2 domain, specifically within craniofacial development. Disruption of C2CD3N-C2 domain in $C 2 c d 3^{\text {ex4-5fl/fl } ; W n t 1 C r e 2 ~ m i c e ~ r e s u l t e d ~}$

\footnotetext{
${ }^{2}$ https://www.ncbi.nlm.nih.gov/gene/277939
} 
in severe craniofacial phenotypes including midfacial widening, palatal clefting and hypoglossia; while deletion of all PKC$\mathrm{C} 2$ domains in $\mathrm{C} 2 c d 3^{\text {ex9fl/fl }}$; Wnt 1 Cre mice produced only mild craniofacial phenotypes. Interestingly, it has been shown that $\mathrm{C} 2 \mathrm{CD} 3$ ortholog SAS-1 in C. elegans contains a unique N-terminal, non-classical C2 domain (von Tobel et al., 2014). SAS-1 also localizes to the centriole and has the ability to bind to and stabilize microtubules. Based on these results, we hypothesize that the $\mathrm{C} 2 \mathrm{CD} 3 \mathrm{~N}-\mathrm{C} 2$ domain may have a distinct and required function when compared to the five PKCC2 domains, specifically in microtubule binding/stabilization, in addition to the known functions in membrane targeting and vesicle docking. Our future studies will address the specific role of the $\mathrm{C} 2 \mathrm{CD} 3 \mathrm{~N}-\mathrm{C} 2$ domain within tissues of the craniofacial complex.

\section{Functional Importance of Ciliary Proteins in Skeletogenesis}

In addition to axial skeletal defects, patients with ciliopathies also frequently present with malformation of the craniofacial skeleton (Baker and Beales, 2009; Schock and Brugmann, 2017). The importance of cilia in skeletal development has been demonstrated in many animal models (Yuan and Yang, 2015). Here we show that deletion of $\mathrm{C} 2 c d 3$ within the progenitors of the craniofacial skeleton (neural crest cells) affected the development of intramembranous skeletal elements. With deletion of all PKC-C2 domains in $\mathrm{C} 2 \mathrm{~cd} 3$, we observed delayed ossifications in the cranial base (palatine bones). Moreover, deletion of $\mathrm{N}$-terminal $\mathrm{C} 2 \mathrm{CD} 3 \mathrm{~N}-\mathrm{C} 2$ domains in addition to all PKC-C2 domains extended the delayed ossifications further to the sphenoid bone. This result was consistent with the previous findings that deletion of ciliary genes Kif $3 a$ or Ift88 using Wnt1-Cre resulted in reduced neural crest cellderived cranial bones (Kolpakova-Hart et al., 2007; Tian et al., 2017). As the majority of the craniofacial skeleton is derived from cranial neural crest cells and differentiates through intramembranous ossification, it will be important to understand how deletion of $\mathrm{C} 2 \mathrm{~cd} 3$ impacts the sequential steps of intramembranous ossification including neural crest condensation, osteoblast/osteocyte differentiation, and matrix/periosteum formation. Our future work will specifically address this question and examine the molecular basis for the onset of these phenotypes.

Mouse models established here can serve as powerful tools to study the function of $\mathrm{C} 2 \mathrm{~cd} 3$ and primary cilia during development of the craniofacial skeleton. Ciliopathy patients with craniofacial anomalies often have abnormal skeletogenesis and require surgical reconstructions using autologous grafts from mesodermal-derived bones like the rib or iliac crest. The surgical process is painful and often the tissue fails to engraft. Using tools like those described herein, we are able to begin understanding cellular and molecular mechanisms necessary for skeletogenesis within the craniofacial complex and potentially apply this knowledge toward the application of alternative surgical repair for OFD, as well as ciliopathy patients, in general.

\section{MATERIALS AND METHODS}

\section{Mice}

Mouse ES cell line $C 2 c d 3^{T M 1 a(E U C O M M) ~ W t s i}$ was purchased from EuMMCR. ${ }^{3}$ ES cell microinjection was performed by Transgenic Animal and Genome Editing (TAGE) Core facility of Cincinnati Children's Hospital Medical Center (CCHMC). The resulting chimeric mice were bred to wild type to obtain heterozygous $\left(\mathrm{C} 2 c d 3^{\mathrm{LacZ} /+}\right)$ animals. CRISPR-targeted $C 2 c d 3$ knockout mice were designed and generated by TAGE Core facility of CCHMC. All animals were maintained by Veterinary Services of CCHMC with IACUC approval.

\section{Analysis of Mutant Embryos}

$\mathrm{C} 2 \mathrm{~cd} 3$ mice were maintained on a CD1 background or serially backcrossed to C57BL/6J. Genotyping for the 8 bp deletion was performed by PCR and Sanger Sequencing. Embryos were harvested via Caesarian section, dissected, and examined. Embryos were fixed in Bouin's fixative overnight at room temperature, washed 3 times with PBS, and imaged on the Leica M165FC microscope.

\section{X-Gal Staining}

$C 2 c d 3^{\mathrm{LacZ} /+}$ embryos at various time points were dissected in cold PBS ( $\mathrm{pH}$ 7.4) and fixed with 2\% Paraformaldehyde (PFA) plus $0.25 \%$ Glutaraldehyde, $0.02 \%$ NP-40, 0.1\% Sodium Deoxycholate in PBS at $4^{\circ} \mathrm{C}$ with gentle shaking for 1-2 hours. The samples were then switched to $\mathrm{X}$-gal staining solution $\left(5 \mathrm{mM} \mathrm{K}_{3} \mathrm{Fe}(\mathrm{CN})_{6}, 5 \mathrm{mM} \mathrm{K}_{4} \mathrm{Fe}(\mathrm{CN})_{6} * 3 \mathrm{H}_{2} \mathrm{O}, 2 \mathrm{mM} \mathrm{MgCl}_{2}\right.$, and $1 \mathrm{mg} / \mathrm{mL} \mathrm{X}$-gal in PBS) at $37^{\circ} \mathrm{C}$ with gentle shaking for 12 16 hours. The staining was terminated with $3 \%$ DMSO in PBS and post-fixed by $4 \%$ PFA in PBS. Whole mount images were taken before obtaining microtome sections.

\section{Western Blot}

Protein lysate was prepared from E9.5 mouse embryos or E11.5 facial prominences (epithelium was removed by treating the samples with $3 \mathrm{mg} / \mathrm{mL}$ Dispase/PBS at $37^{\circ} \mathrm{C}$ for $30 \mathrm{~min}$ ) in RIPA buffer with protease and phosphatase inhibitors and $20 \mu \mathrm{g}$ of sample was loaded onto 3-8\% NuPAGE Tris-Acetate gels (ThermoFisher) for Western blot. C2cd3 (1:500; Antibodiesonline.com ABIN2591132), Gli3 (1:1,000; R\&D Systems, AF3690), and Vinculin (1:2,000; Santa Cruz, sc-73614) antibodies were used. Blots were imaged on LICOR Odyssey imager.

\section{Immunofluorescence Staining}

Cryosections of E9.5 embryos were fixed in 4\% PFA for $5 \mathrm{~min}$, washed three times with PBS. The sections were then blocked in $5 \%$ normal goat serum in PBS for $30 \mathrm{~min}$ and then incubated with Arl13b (1:1,000; Proteintech, 17711-1-AP) and gammaTubulin (1:1,000; Sigma, T6557) in blocking buffer at $4^{\circ} \mathrm{C}$ overnight. Goat anti-rabbit Alexa 488 and goat anti-mouse Alexa 594 were used for secondary antibodies at 1:1,000 in blocking buffer, room temperature, 1-2 h. DAPI $(1: 10,000)$ was used for nuclear staining.

\footnotetext{
${ }^{3}$ https://www.eummcr.org
} 


\section{MiniMUGA Genotyping}

MiniMUGA (Mouse Universal Genotyping Array genotyping, Neogen Genomics Co.) genotyping was performed by GeneSeek (Neogen; Lincoln, NE, United States). Genomic DNA was isolated using ThermoFisher PureLink gDNA kit. Approximately 10,800 markers were analyzed with MiniMUGA.

\section{DATA AVAILABILITY STATEMENT}

The datasets presented in this study can be found in online repositories. The names of the repository/repositories and accession number(s) can be found in the article/ Supplementary Material.

\section{ETHICS STATEMENT}

The animal study was reviewed and approved by Veterinary Services of CCHMC with IACUC approval.

\section{AUTHOR CONTRIBUTIONS}

C-FC performed all embryonic and expression analysis. KB and YY performed all backcrossing studies and genetic background analysis. SB conceived and funded project. SB, C-FC, and KB wrote and edited manuscript. All authors contributed to the article and approved the submitted version.

\section{FUNDING}

This study was funded by the National Institutes of Health (R35 DE027557) and Shriners Hospital for Children (543938) to SB.

\section{REFERENCES}

Badano, J. L., Leitch, C. C., Ansley, S. J., May-Simera, H., Lawson, S., Lewis, R. A., et al. (2006). Dissection of epistasis in oligogenic Bardet-Biedl syndrome. Nature 439, 326-330. doi: 10.1038/nature04370

Baker, K., and Beales, P. L. (2009). Making sense of cilia in disease: the human ciliopathies. Am. J. Med. Genet. C Semin. Med. Genet. 151C, 281-295. doi: 10.1002/ajmg.c.30231

Bhattacharyya, S., Rainey, M. A., Arya, P., Mohapatra, B. C., Mushtaq, I., Dutta, S., et al. (2016). Endocytic recycling protein EHD1 regulates primary cilia morphogenesis and SHH signaling during neural tube development. Sci. Rep. 6:20727.

Boczek, N. J., Hopp, K., Benoit, L., Kraft, D., Cousin, M. A., Blackburn, P. R., et al. (2018). Characterization of three ciliopathy pedigrees expands the phenotype associated with biallelic C2CD3 variants. Eur. J. Hum. Genet. 26, 1797-1809. doi: 10.1038/s41431-018-0222-3

Bruel, A. L., Franco, B., Duffourd, Y., Thevenon, J., Jego, L., Lopez, E., et al. (2017). Fifteen years of research on oral-facial-digital syndromes: from 1 to 16 causal genes. J. Med. Genet. 54, 371-380.

Burke, M. C., Li, F. Q., Cyge, B., Arashiro, T., Brechbuhl, H. M., Chen, X., et al. (2014). Chibby promotes ciliary vesicle formation and basal body docking during airway cell differentiation. J. Cell Biol. 207, 123-137. doi: 10.1083/jcb. 201406140

\section{ACKNOWLEDGMENTS}

We would like to thank Lisa Lemen for assistance in microCT acquisition and analysis (Preclinical Imaging Core - University of Cincinnati) and Yueh-Chiang $\mathrm{Hu}$ (The Transgenic Animal and Genome Editing Core-CCHMC). We would also like to thank members of the Brugmann lab for helpful comments and feedback.

\section{SUPPLEMENTARY MATERIAL}

The Supplementary Material for this article can be found online at: https://www.frontiersin.org/articles/10.3389/fcell.2021. 647391/full\#supplementary-material

Supplementary Figure 1 | Reported splice variants in murine C2cd3. Seven protein-coding variants ( $\mathrm{NCBI}$ accession number NM or XM) produce four protein isoforms (one non-coding mRNA is also predicted (XR_003946487.1, not shown)). Two isoforms contain $\mathrm{C} 2 \mathrm{CD} 3 \mathrm{~N}-\mathrm{C} 2$ domain $(\mathbf{A}, \mathbf{C})$ while two isoforms contain only PKC-C2 domains (B,D).

Supplementary Figure 2 | (A) Western blot of Gli3FL and Gli3R in CD1 and C57BL/6J backgrounds. (B) Densitometry of Gli3FL and Gli3R in each lane was measured by ImageJ. Gli3FL/Gli3R ratio is higher on C57BL/6J background ( $n=4, t$-test, ${ }^{*}$ indicates $\left.P<0.05\right)$.

Supplementary Figure 3 | Exon expression in C2cd3 mutants. (A) RT-qPCR of exon 8-9 and 32-33 in wild-type $(n=5), C 2 c d 3^{e x 2 /+}(n=6)$, and $C 2 c d 3^{e x 2 / e x 2}$ $(n=4)$ embryos shows significantly reduced, but detectable levels of $C 2 c d 3$ downstream of exon 2 ( $t$-test, ${ }^{*}$ indicates $P<0.05$; ** indicates $P<0.01$; NS: not significant).

Supplementary Figure 4 | MicroCT analysis of E17.5 mouse embryos. Snapshots of microCT 3D images of $\left(\mathbf{A}, \mathbf{A}^{\prime}\right)$ wild type and $\left.\mathbf{( B ,}, \mathbf{B}^{\prime}\right)$ C2cd3 $3^{\text {ex9f//fl; } W n t 1 C r e ~ m u t a n t ~ e m b r y o s . ~ T h e ~ f r o n t a l ~ b o n e s ~}(\mathbf{A}, \mathbf{B})$ and mandibular bones $\left(\mathbf{A}^{\prime}, \mathbf{B}^{\prime}\right)$ are marked by blue. The bone volume of $\mathbf{( C )}$ frontal bones and mandibular bones (D) was measured by Inveon Workstation Software (Siemens Medical Inc), the results indicates that there is no significant difference between wild type and mutant ( $n=4$ for wild type or mutant, $t$-test, NS: not significant).

Chang, C. F., Schock, E. N., O’Hare, E. A., Dodgson, J., Cheng, H. H., Muir, W. M., et al. (2014). The cellular and molecular etiology of the craniofacial defects in the avian ciliopathic mutant talpid2. Development 141, 3003-3012. doi: 10.1242/dev.105924

Cortes, C. R., McInerney-Leo, A. M., Vogel, I., Rondon Galeano, M. C., Leo, P. J., Harris, J. E., et al. (2016). Mutations in human C2CD3 cause skeletal dysplasia and provide new insights into phenotypic and cellular consequences of altered C2CD3 function. Sci. Rep. 6:24083.

Djordjevic, S., and Driscoll, P. C. (2002). Structural insight into substrate specificity and regulatory mechanisms of phosphoinositide 3-kinases. Trends Biochem. Sci. 27, 426-432. doi: 10.1016/s0968-0004(02)02136-9

Farah, C. A., and Sossin, W. S. (2012). The role of C2 domains in PKC signaling. Adv. Exp. Med. Biol. 740, 663-683. doi: 10.1007/978-94-007-2888-2_29

Farley, F. W., Soriano, P., Steffen, L. S., and Dymecki, S. M. (2000). Widespread recombinase expression using FLPeR (flipper) mice. Genesis 28, 106-110. doi: 10.1002/1526-968x(200011/12)28:3/4<106::aid-gene30>3.0.co;2-t

Franco, B., and Thauvin-Robinet, C. (2016). Update on oral-facial-digital syndromes (OFDS). Cilia 5:12.

Hamilton, B. A., and Yu, B. D. (2012). Modifier genes and the plasticity of genetic networks in mice. PLoS Genet. 8:e1002644. doi: 10.1371/journal.pgen.1002644

Hoover, A. N., Wynkoop, A., Zeng, H., Jia, J., Niswander, L. A., and Liu, A. (2008). C2cd3 is required for cilia formation and Hedgehog signaling in mouse. Development 135, 4049-4058. doi: 10.1242/dev.029835 
Hsiao, Y. C., Tong, Z. J., Westfall, J. E., Ault, J. G., Page-McCaw, P. S., and Ferland, R. J. (2009). Ahil, whose human ortholog is mutated in Joubert syndrome, is required for Rab8a localization, ciliogenesis and vesicle trafficking. Hum. Mol. Genet. 18, 3926-3941. doi: 10.1093/hmg/ddp335

Jones, N. C., Lynn, M. L., Gaudenz, K., Sakai, D., Aoto, K., Rey, J. P., et al. (2008). Prevention of the neurocristopathy Treacher Collins syndrome through inhibition of p53 function. Nat. Med. 14, 125-133. doi: 10.1038/nm1725

Joukov, V., and De Nicolo, A. (2019). The centrosome and the primary cilium: the yin and yang of a hybrid organelle. Cells 8:701. doi: 10.3390/cells8070701

Kazatskaya, A., Kuhns, S., Lambacher, N. J., Kennedy, J. E., Brear, A. G., McManus, G. J., et al. (2017). Primary cilium formation and ciliary protein trafficking is regulated by the atypical MAP Kinase MAPK15 in Caenorhabditis elegans and human cells. Genetics 207, 1423-1440. doi: 10.1534/genetics.117.300383

Kelemen, O., Convertini, P., Zhang, Z., Wen, Y., Shen, M., Falaleeva, M., et al. (2013). Function of alternative splicing. Gene 514, 1-30. doi: 10.1002/ 9783527678679.dg00350

Kobayashi, T., Kim, S., Lin, Y. C., Inoue, T., and Dynlacht, B. D. (2014). The CP110interacting proteins Talpid3 and Cep290 play overlapping and distinct roles in cilia assembly. J. Cell Biol. 204, 215-229. doi: 10.1083/jcb.201304153

Kolpakova-Hart, E., Jinnin, M., Hou, B., Fukai, N., and Olsen, B. R. (2007). Kinesin2 controls development and patterning of the vertebrate skeleton by Hedgehogand Gli3-dependent mechanisms. Dev. Biol. 309, 273-284. doi: 10.1016/j.ydbio. 2007.07.018

Kousi, M., and Katsanis, N. (2015). Genetic modifiers and oligogenic inheritance. Cold Spring Harb. Perspect. Med. 5:a017145. doi: 10.1101/cshperspect.a017145

Lee, J. O., Yang, H., Georgescu, M. M., Di Cristofano, A., Maehama, T., Shi, Y., et al. (1999). Crystal structure of the PTEN tumor suppressor: implications for its phosphoinositide phosphatase activity and membrane association. Cell 99, 323-334.

Lewis, A. E., Vasudevan, H. N., O’Neill, A. K., Soriano, P., and Bush, J. O. (2013). The widely used Wnt1-Cre transgene causes developmental phenotypes by ectopic activation of Wnt signaling. Dev. Biol. 379, 229-234. doi: 10.1016/j. ydbio.2013.04.026

Louie, C. M., Caridi, G., Lopes, V. S., Brancati, F., Kispert, A., Lancaster, M. A., et al. (2010). AHI1 is required for photoreceptor outer segment development and is a modifier for retinal degeneration in nephronophthisis. Nat. Genet. 42, 175-180. doi: 10.1038/ng.519

Lu, Q., Insinna, C., Ott, C., Stauffer, J., Pintado, P. A., Rahajeng, J., et al. (2015). Early steps in primary cilium assembly require EHD1/EHD3-dependent ciliary vesicle formation. Nat. Cell Biol. 17, 228-240. doi: 10.1038/ncb3109

Morgan, A. P., Fu, C. P., Kao, C. Y., Welsh, C. E., Didion, J. P., Yadgary, L., et al. (2015). The mouse universal genotyping array: from substrains to subspecies. G3 (Bethesda) 6, 263-279. doi: 10.1534/g3.115.022087

Nadeau, J. H. (2001). Modifier genes in mice and humans. Nat. Rev. Genet. 2, 165-174. doi: 10.1038/35056009

Reiter, J. F., and Leroux, M. R. (2017). Genes and molecular pathways underpinning ciliopathies. Nat. Rev. Mol. Cell Biol. 18, 533-547. doi: 10.1038/ nrm. 2017.60

Remans, K., Burger, M., Vetter, I. R., and Wittinghofer, A. (2014). C2 domains as protein-protein interaction modules in the ciliary transition zone. Cell Rep. 8, 1-9. doi: 10.1016/j.celrep.2014.05.049

Schmidt, K. N., Kuhns, S., Neuner, A., Hub, B., Zentgraf, H., and Pereira, G. (2012). Cep164 mediates vesicular docking to the mother centriole during early steps of ciliogenesis. J. Cell Biol. 199, 1083-1101. doi: 10.1083/jcb.201202126
Schock, E. N., and Brugmann, S. A. (2017). Discovery, diagnosis, and etiology of craniofacial ciliopathies. Cold Spring Harb. Perspect. Biol. 9:a028258. doi: $10.1101 /$ cshperspect.a028258

Schock, E. N., Chang, C. F., Struve, J. N., Chang, Y. T., Chang, J., Delany, M. E., et al. (2015). Using the avian mutant talpid2 as a disease model for understanding the oral-facial phenotypes of oral-facial-digital syndrome. Dis. Model. Mech. 8, $855-866$.

Sharma, A., Gerard, S. F., Olieric, N., and Steinmetz, M. O. (2018). Cep120 promotes microtubule formation through a unique tubulin binding $\mathrm{C} 2$ domain. J. Struct. Biol. 203, 62-70. doi: 10.1016/j.jsb.2018.01.009

Singla, V., Romaguera-Ros, M., Garcia-Verdugo, J. M., and Reiter, J. F. (2010). Ofd1, a human disease gene, regulates the length and distal structure of centrioles. Dev. Cell 18, 410-424. doi: 10.1016/j.devcel.2009.12.022

Snedeker, J., Gibbons, W. J. Jr., Paulding, D. F., Abdelhamed, Z., Prows, D. R., and Stottmann, R. W. (2019). Gpr63 is a modifier of microcephaly in Ttc21b mouse mutants. PLoS Genet. 15:e1008467. doi: 10.1371/journal.pgen.1008467

Steinberg, S. F. (2008). Structural basis of protein kinase C isoform function. Physiol. Rev. 88, 1341-1378. doi: 10.1152/physrev.00034.2007

Thauvin-Robinet, C., Lee, J. S., Lopez, E., Herranz-Perez, V., Shida, T., Franco, B., et al. (2014). The oral-facial-digital syndrome gene C2CD3 encodes a positive regulator of centriole elongation. Nat. Genet. 46, 905-911. doi: 10.1038/ ng.3031

Tian, H., Feng, J., Li, J., Ho, T. V., Yuan, Y., Liu, Y., et al. (2017). Intraflagellar transport 88 (IFT88) is crucial for craniofacial development in mice and is a candidate gene for human cleft lip and palate. Hum. Mol. Genet. 26, 860-872.

von Tobel, L., Mikeladze-Dvali, T., Delattre, M., Balestra, F. R., Blanchoud, S., Finger, S., et al. (2014). SAS-1 is a C2 domain protein critical for centriole integrity in C. elegans. PLoS Genet. 10:e1004777. doi: 10.1371/journal.pgen. 1004777

Wang, L., and Dynlacht, B. D. (2018). The regulation of cilium assembly and disassembly in development and disease. Development 145:dev151407.

Ye, X., Zeng, H., Ning, G., Reiter, J. F., and Liu, A. (2014). C2cd3 is critical for centriolar distal appendage assembly and ciliary vesicle docking in mammals. Proc. Natl. Acad. Sci. U.S.A. 111, 2164-2169. doi: 10.1073/pnas.1318737111

Yuan, X., and Yang, S. (2015). Cilia/Ift protein and motor -related bone diseases and mouse models. Front. Biosci. 20:515-555. doi: 10.2741/4323

Zhang, D., and Aravind, L. (2010). Identification of novel families and classification of the C2 domain superfamily elucidate the origin and evolution of membrane targeting activities in eukaryotes. Gene 469, 18-30. doi: 10.1016/j.gene.2010.08. 006

Zhang, D., and Aravind, L. (2012). Novel transglutaminase-like peptidase and C2 domains elucidate the structure, biogenesis and evolution of the ciliary compartment. Cell Cycle 11, 3861-3875. doi: 10.4161/cc.22068

Conflict of Interest: The authors declare that the research was conducted in the absence of any commercial or financial relationships that could be construed as a potential conflict of interest.

Copyright (c) 2021 Chang, Brown, Yang and Brugmann. This is an open-access article distributed under the terms of the Creative Commons Attribution License (CC BY). The use, distribution or reproduction in other forums is permitted, provided the original author(s) and the copyright owner(s) are credited and that the original publication in this journal is cited, in accordance with accepted academic practice. No use, distribution or reproduction is permitted which does not comply with these terms. 